\section{Managing behavioural and psychological symptoms}

\section{in dementia}

\author{
BRIAN LAWLOR
}

Behavioural and psychological symptoms of dementia (BPSD) are common and problematic in clinical practice and represent a significant part of the day-to-day workload of the old age psychiatry team in hospital, institution and community settings. Improving our recognition and management of BPSD can have a positive impact on the quality of life of our patients and their carers and potentially delay the transition from home to institutional care.

\section{DEFINITION}

Behavioural and psychological symptoms in dementia is an umbrella term that embraces a heterogeneous group of noncognitive symptoms and behaviours that occur in people with dementia. The concept of BPSD is a descriptive one and does not reflect a diagnostic entity but rather highlights an important clinical dimension of dementia that has until recently been ignored from both research and therapeutic points of view. One approach to the description of BPSD is the use of a list of observed behaviours (wandering, agitation, sexually inappropriate behaviours) and elicited psychological symptoms (depression, anxiety, delusions) (Finkel et al, 1996). This approach fails to take into account the fact that many so-called elicited symptoms (depression, delusions) also represent observed behaviours ('looks depressed', 'acts as though hallucinating or deluded'), and the fact that most of these symptoms and behaviours do not occur in isolation but tend to occur together in clusters or syndromes. A number of syndromes have been described on the basis of factor analytical studies using rating instruments designed to measure BPSD (Frisoni et al, 1999). These syndromes include depression, psychosis, psychomotor agitation, aggression and apathy. Both depression and psychosis are included as descriptors in the DSM-IV criteria for Alzheimer's disease (American Psychiatric Association, 1994) and, more recently, diagnostic criteria for a distinct syndrome of psychosis of Alzheimer's disease and related dementias and for depression of Alzheimer's disease have been proposed (Jeste \& Finkel, 2000; Olin et al, 2002). It is likely that diagnostic criteria for other behavioural syndromes of dementia will also be developed in the near future and this will facilitate recognition and future therapeutic targeting of more specific aspects of BPSD.

\section{PREVALENCE} symptoms are not included as core features in the definition of the dementia syndrome, about two-thirds of people with dementia experience some BPSD at any one time point, and for one-third of communitydwelling people with dementia the level of BPSD will be in the clinically significant range (Lyketsos et al, 2000). The figure for clinically significant BPSD rises to almost $80 \%$ for people with dementia residing in care environments (MargalloLana $e t a l, 2001)$. Prevalence estimates for BPSD vary widely because of the heterogeneity of patient populations studied in terms of setting and type of dementia, and the different definitions used for BPSD. The recent application of standardised and validated assessment instruments is resulting in more consistent data for communityand clinic-based populations. Two population-based studies, one from the USA (Lyketsos et al, 2000) and one from the UK (Burns et al, 1990), show similar prevalence figures of about $20 \%$ for BPSD in people with Alzheimer's disease. Unlike the cognitive dysfunction in dementia, which progressively worsens over time, many BPSD tend to fluctuate, with psycho(Devanand et al, 1997). Further research is needed into the natural history and
Although behaviour and psychological motor agitation being the most persistent longitudinal course of BPSD to inform clinicians about the appropriate duration of pharmacological interventions and what advice and information should be given to families distressed by these symptoms and behaviours.

\section{IMPACT}

The occurrence of BPSD is often the triggering event for recognition and referral of people with dementia to specialist services, to which patients and families present in crisis and disarray, relatively late in the course of the illness. The development of BPSD is a major risk factor for caregiver burden (Coen et al, 1997) and institutionalisation (O'Donnell et al, 1992), and is more important in this regard than the enduring cognitive deficits of the disease process (Steele et al, 1990). All aspects of BPSD can be associated with caregiver burden, but paranoia, aggression and sleep-wake cycle disturbance appear to be particularly important drivers of caregiver burden and institutionalisation (O'Donnell et al, 1992). The development of BPSD is also associated with a worse prognosis and a more rapid rate of illness progression (Paulsen $e t$ al, 2000), and adds significantly to the direct and indirect costs of care. Expert assessment and targeted treatment of BPSD can alleviate patient suffering and promote caregiver well-being, but will be less effective if interventions occur after the support system has been ruptured.

\section{MANAGEMENT APPROACHES}

In the assessment of individuals with dementia at all stages of the illness, careful enquiry must be made regarding the presence of BPSD. The emphasis here must be to detect BPSD before caregiver burnout and irretrievable damage to the support environment occur. Just as the collateral history and the use of an objective performance-based test must be part of any comprehensive cognitive assessment, so too should the history and assessment focus on behavioural and psychological symptoms, given their high frequency and impact on both patient and caregiver quality of life.

Recognition of BPSD is the first and most important step in devising a management plan and will be facilitated by the use of standardised assessment scales such as the Behavioural Pathology in 
Alzheimer's Disease Rating Scale (BehaveAD) (Reisberg et al, 1987) or the Neuropsychiatric Inventory (NPI; Cummings et al, 1994). The characteristics of the behaviour or symptoms together with the frequency, severity and impact on the patient and caregiver must be identified before formulating a tailored and targeted plan of action which is likely to involve pharmacological and non-pharmacological interventions. It is useful to identify target syndromes in the patient: is this primarily a psychotic syndrome (hallucinations or delusions), or is the main problem psychomotor agitation and sleep disturbance? The context of the behaviour or symptom and its impact are also key elements in assessment. Aggressive resistance when a personal activity is being carried out with the patient may not warrant immediate pharmacological intervention. Also, misidentification symptoms as part of a psychotic syndrome can be more distressing to carers than to patients and in such instances education of family members rather than drug treatment is required.

\section{Pharmacological treatments}

Drug treatments in BPSD should be evidence-based and targeted to specific syndromes that are clinically significant because of their frequency, pervasiveness or impact. For depression in dementia, although there is little placebo-controlled evidence to guide practice, clinical experience indicates that selective serotonin reuptake inhibitors are safe and effective. Neuroleptic agents have been shown to be more effective than placebo for aggression, psychosis and agitation in dementia (Devanand et al, 1998; De Deyn et al, 1999; Street et al, 2000), and novel agents are superior to conventional neuroleptics in terms of tolerability and sideeffect profile. Non-neuroleptic treatments such as carbamazepine have demonstrated efficacy over placebo in the treatment of agitation (Tariot et al, 1998). Recent placebo-controlled studies suggest that cholinesterase inhibitors improve the apathetic syndrome in Alzheimer's disease and also decrease psychotic symptoms, particularly hallucinations, in Alzheimer's disease and Lewy body dementia (Cummings, 2000; McKeith et al, 2000).

\section{Non-pharmacological treatments}

There is a dearth of controlled evidence for psychological interventions in BPSD.

BRIAN LAWLOR, FRCPsych, Jonathan Swift Clinic, Department of Psychiatry, St James's Hospital, St James Street, Dublin 8, Ireland

(First received 16 January 2002, accepted 29 April 2002)

Individualised music therapy, bright light treatment and specific behaviour interventions have been found to improve certain troubling behavioural symptoms in dementia, but more evidence is required in this area (Devanand \& Lawlor, 2000).

\section{Interventions for the carer}

Boosting caregiver support, increasing 'time for self' and providing carer education and training in the management of BPSD can be effective in decreasing burden and mollifying its impact on the carer (Ostwald et al, 1999). Interventions with carers may not only decrease carer burden and improve the tolerability of the particular symptom (Hepburn et al, 2001) but can also have a positive impact on patient behaviour (Marriott et al, 2000) and possibly delay institutionalisation (Brodaty et al, 1993; Teri, 1999).

\section{TRAINING AND EDUCATION}

The behavioural and psychological symptoms of dementia are now accepted as an important therapeutic target. Management strategies, including pharmacological and non-pharmacological treatments, together with carer-focused training and education approaches, can be effective in decreasing BPSD but require concerted multi-disciplinary team input. While the old age psychiatry team is well positioned to address the care needs of patients with BPSD, there are certain resource and training needs attached to the delivery of such care. Some degree of special interest development in the area of BPSD should be encouraged within the multi-disciplinary team and the adoption of evidence-based guidelines and standardised assessments promoted. Ongoing training and professional education of team members in BPSD should be given priority so that the highest standards of care can be provided for patients and their carers.

\section{DECLARATION OF INTEREST}

B.L. has received honoraria and hospitality from pharmaceutical companies working in the fields of Alzheimer's disease and behavioural and psychological symptoms in dementia.

\section{REFERENCES}

American Psychiatric Association (1994) Diagnostic and Statistical Manual of Mental Disorders (4th edn) (DSM-IV). Washington, DC: APA.

Brodaty, H., McGilchrist, C., Harris, L., et al (1993) Time until institutionalization and death in patients with dementia. Role of caregiver training and risk factors. Archives of Neurology, 50, 643-650.

Burns, A., Jacoby, R. \& Levy, R. (1990) Psychiatric phenomena in Alzheimer's disease. I: Disorders of thought content. British Journal of Psychiatry, 157, 72-76.

Coen, R. F., Swanwick, G. R., O'Boyle, C. A., et al (1997) Behaviour disturbance and other predictors of carer burden in Alzheimer's disease. International Journal of Geriatric Psychiatry, 12, 331-336.

Cummings, J. L. (2000) Cholinesterase inhibitors: a new class of psychotropic compounds. American Journal of Psychiatry, 157, 4-15.

_, Mega, M., Gray, K., et al (1994) The

Neuropsychiatric Inventory: comprehensive assessment of psychopathology in dementia. Neurology, 44, 2308 2314

De Deyn, P. P., Rabheru, K., Rasmussen, A., et a (1999) A randomised trial of risperidone, placebo and haloperidol for behavioral symptoms of dementia. Neurology, 53, 946-955.

Devanand, D. P. \& Lawlor, B. A. (2000) Treatment of Behavioral and Psychological Symptoms of Dementia. London: Martin Dunitz.

_ , Jacobs, D. M., Tang, M. X., et al (1997) The course of psychopathologic features in mild to moderate Alzheimer disease. Archives of General Psychiatry, 54, 257-263.

_ , Marder, K., Michaels, K. S., et al (1998) A

randomized, placebo-controlled dose-comparison trial of haloperidol for psychosis and disruptive behaviors in Alzheimer's disease. American Journal of Psychiatry, 155 1512-1520.

Finkel, S. I., Costa e Silva, J., Cohen, G., et al (1996) Behavioral and psychological signs and symptoms of dementia: a consensus statement on current knowledge and implications for research and treatment. International Psychogeriatrics, 8 (suppl. 3), 497-500.

Frisoni, G. B., Rozzini, L., Gozzetti, A., et al (1999) Behavioral syndromes in Alzheimer's disease: description and correlates. Dementia and Geriatric Cognitive Disorders, 10, 130-138.

Hepburn, K. W., Tornatore, J., Center, B., et al (200I) Dementia family caregiver training: affecting beliefs about caregiving and caregiver outcomes. Journal of the American Geriatric Society, 49, 450-457.

Jeste, D. V. \& Finkel, S. I. (2000) Psychosis of Alzheimer's disease and related dementias. Diagnostic criteria for a distinct syndrome. American Journal of Geriatric Psychiatry, 8, 29-34. 
Lyketsos, C. G., Steinberg, M., Tschanz, J. T., et al (2000) Mental and behavioral disturbances in dementia: findings from Cache County Study on Memory and Aging. American Journal of Psychiatry, 157, 708-714.

Margallo-Lana, M., Swann, A., O'Brien, J., et al

(200I) Prevalence and pharmacological management of behavioural and psychological symptoms amongst dementia sufferers living in care environments. International Journal of Geriatric Psychiatry, 16, 39-44.

McKeith, I., Del Ser, T., Spano, P., et al (2000) Efficacy of rivastigmine in dementia with Lewy bodies: a randomised, double-blind, placebo-controlled international study. Lancet, 356, 203I-2036.

Marriott, A., Donaldson, C., Tarrier, N., et al (2000) Effectiveness of cognitive-behavioural family intervention in reducing the burden of care in carers of patients with Alzheimer's disease. British Journal of Psychiatry, 176, 557-562.
O'Donnell, B. F., Drachman, D. A., Barned, H. J., et al (1992) Incontinence and troublesome behaviors predict institutionalisation in dementia. Journal of Geriatric Psychiatry and Neurology, 5, 45-52.

Olin, J. T., Schneider, L. S., Katz, I. R., et al (2002) Provisional diagnostic criteria for depression of Alzheimer's disease. American Journal of Geriatric Psychiatry, 10, 125-128.

Ostwald, S. K., Hepburn, K.W., Caron, W., et al (1999) Reducing caregiver burden: a randomized psychoeducational intervention for caregivers of persons with dementia. Gerontologist, 39, 299-309.

Paulsen, J. S., Salmon, D. P., Thai, L. J., et al (2000) Incidence of and risk factors for hallucinations and delusions in patients with probable AD. Neurology, $\mathbf{5 4}$ 1965-1971.

Reisberg, B., Borenstein, J., Salob, S. P., et al (1987) Behavioral symptoms in Alzheimer's disease: phenomenology and treatment. Journal of Clinical Psychiatry, 48 (suppl.), 9-15.

Steele, C., Rovner, B., Chase, G. A., et al (1990) Psychiatric symptoms and nursing home placement of patients with Alzheimer's disease. American Journal of Psychiatry, 147, |049-105|.

Street, J., Clark, W. S., Gannon, K. S., et al (2000) Olanzapine treatment of psychotic and behavioral symptoms in patients with Alzheimer's disease in nursing care facilities: a double-blind placebo-controlled trial. The HGEU Group. Archives of General Psychiatry, 57, 968-976.

Tariot, P. N., Erb, R., Podgorski, C. A., et al (1998) Efficacy and tolerability of carbamazepine for agitation and aggression in dementia. American journal of Psychiatry, I55, 54-61.

Teri, L. (1999) Training families to provide care: effects on people with dementia. International journal of Geriatric Psychiatry, 14, 110-116. 